\title{
The effects of isoflavones on bone density in postmenopausal women at tertiary centre
}

\author{
Neetu Singh ${ }^{1}$, Dileep Kumar ${ }^{2} *$, Preeti Dubey ${ }^{3}$, Ani Chandanan ${ }^{1}$, Priya $\operatorname{Singh}^{1}$ \\ ${ }^{1}$ Department of Obstetrics \& Gynaecology, GSVM Medical College, Kanpur, UP, India \\ ${ }^{2}$ DPMR (RALC) KGMU Lucknow, UP, India \\ ${ }^{3}$ Department of Obstetrics \& Gynaecology, Mahamaya Medical College, Ambedkar Nagar UP , India
}

Received: 02 September 2015

Revised: 03 October 2015

Accepted: 16 October 2015

\author{
*Correspondence: \\ Dr. Dileep kumar, \\ E-mail: dileeomsortho@yahoo.com
}

Copyright: $\odot$ the author(s), publisher and licensee Medip Academy. This is an open-access article distributed under the terms of the Creative Commons Attribution Non-Commercial License, which permits unrestricted non-commercial use, distribution, and reproduction in any medium, provided the original work is properly cited.

\begin{abstract}
Background: The objective of study was to study the effect of isoflavone supplement on bone density of postmenopausal women.

Methods: Women aged 49-65 y $(\mathrm{n}=205)$ were enrolled in a double-blind, prospective randomized, placebocontrolled trial; 177 completed the trial. Bone density, body composition, bone turnover markers and diet were measured at baseline and after 12 months.

Results: Loss of lumbar spine bone mineral content and bone mineral density was significantly lower in the women taking the isoflavone supplement than in those taking the placebo. Interactions between treatment group and menopausal status with respect to changes in other outcomes were not significant.

Conclusions: These data suggest that, through attenuation of bone loss, isoflavones have a potentially protective effect on the lumbar spine and femur neck in women.
\end{abstract}

Keywords: Isoflavones, Phytoestrogens, Bone density

\section{INTRODUCTION}

Osteoporosis has emerged a major health hazard in postmenopausal women. There is decrease mass per unit volume (density) of bone matrix (osteoid) maintaining the bone brittle and labile to break especially hip, vertebra and wrist. ${ }^{1}$ The process accelerate two year prior to menopause, reaching the peak level during first 3 years of menopause when women loss 3-5\% of their bone mass per year. ${ }^{2}$ Estrogens play an important role in skeletal homeostasis, and ovarian hormone deficiency is one of the most important risk factors for osteoporosis. Estrogen is helpful in maintaining bone health by increasing osteoclast apoptosis and decreasing cytokines which promotes osteoclast activity. ${ }^{3}$ There are clear bone- related benefits of hormone replacement therapy (HRT), but compliance with such regimens is generally very poor, partly as a result of fears about the risks of cancer. HRT increases the risk of breast and endometrial cancer. ${ }^{4}$ Phytoestrogens are plant derived compounds with estrogenic activity found in natural diet including soybean, soy product and alfafa fodders used widely for prevention and treatment of osteoporosis. ${ }^{5}$ Isoflavones are compounds in plant foods, particularly soybeans, that are structurally similar to the mammalian estrogens and that have received considerable attention for their potential bone-sparing properties. Rates of hip fracture in Asian populations, whose traditional diets are rich in soy, are substantially lower than those in whites residing in the United States. In humans, some but not all cross-sectional 
studies in Asian populations reported significant positive associations between soy protein or isoflavone intakes and BMD. Furthermore, intervention trials in humans using either soy protein or isoflavone extracts generally reported protective effects on bone, although sample sizes were small and trials often were relatively short.

We aimed to determine the effects of consuming isoflavone supplement for 1 year on the BMD of the lumbar spine and hip, on biochemical markers of bone turnover, and on body composition.

\section{METHODS}

This prospective, randomized double blind study was carried out at Upper India Sugar Exchange Maternity Hospital in Kanpur. Women aged 49-65 yr. were recruited from the outpatient department. A total of 85 women were randomly assigned to receive isoflavone or placebo tablets. Participants were randomly assigned to receive daily either an isoflavone tablet or a placebo of identical appearance. This prospective randomized control study was carried out at UISEMH from January 2012 to June 2013

Postmenopausal women included in study. Inclusion criteria were last menstrual period at least 12 months back or 6 weeks since bilateral oophorectomy not using lipid lowering drugs. Exclusion criteria were undiagnosed vaginal bleeding, history of breast and endometrial cancer and active liver disease. An informed consent was taken from the participants educating them about possible benefits of therapy. Other group was placebo group. Both groups received calcium $1000 \mathrm{mg}$ and vitamin D 800 IU/day. Study group received isoflavones in $120 \mathrm{mg}$ dose.

Apart from clinical evaluation or by detailed history, physical and gynaecological examination also done. Bone density was assessed by dual energy X-ray absorptiometry (DXA) at baseline and after 12 months. Individual scans of the lumbar spine (L1-L4) and hip (femoral neck) were taken. Participants' height and weight were measured at the time of the DXA scans, and body mass index (BMI) was calculated as [weight $(\mathrm{kg}) /$ height $(\mathrm{m} 2)$ ]. Statistical analysis was performed using SPSS (version 10) statistical software package.

\section{RESULTS}

Baseline characteristics of the study group are shown in Table I.44 women were enrolled in Isoflavones group. Rest 41 were enrolled in placebo group. Mean age for isoflavone group is $55.1 \pm 4.72$ years and mean age for placebo group is $55.2 \pm 4.9$ years. Differences between age group are insignificant ( $\mathrm{p}$ value-0.923). Other point in table 1 is years since menopause. Mean years since menopause in isoflavone group is $6.30 \pm 5.7$ years and mean years since menopause in placebo group is $5.99 \pm 3.91$ years. The difference between mean years is insignificant ( $p$ value-0.924). Mean BMI for isoflavone group is $25.44 \pm 4.18$ and mean BMI for placebo group is 25.53 44.7. Differences between BMI are insignificant ( $p$ value-0.926).

Changes in bone mineral density of femur neck and lumber spine of both groups after 1 year of treatment are shown in Table II. Mean BMD of femur neck at 0 month for isoflavone group is $0.84 \pm 0.12$ and for placebo group is $0.82 \pm 0.10$. Difference between mean BMD of both groups at 0 month is insignificant ( $p$ value-0.06). Mean $\mathrm{BMD}$ of lumber spine at 0 month for isoflavone group is $0.86 \pm 0.12$ and for placebo group is $0.81 \pm 0.12$. Difference between mean BMD of both groups at 0 month is insignificant ( $p$ value-0.103). After 1 year of treatment mean BMD of femur neck at 12 months for isoflavone group is $0.90 \pm 0.12$ and for placebo group is $0.84 \pm 0.10$. Difference between mean BMD of both groups at 12 months is significant ( $p$ value-0.015). Mean BMD of lumber spine at 12 months for isoflavone group is $0.92 \pm 0.12$ and for placebo group is $0.83 \pm 0.12$. Difference between mean BMD of both groups at 12 months is also significant ( $\mathrm{p}$ value-0.024).

\section{DISCUSSION}

Phytoestrogens have generated a lot of interest in last two decades as a natural approach to the management of menopause and many studies have been conducted using soy isoflavones either as a part of protein supplement or as purified extract tablets and red clover isoflavones. Because of both the structural similarity of isoflavones to mammalian estrogens and their ability to bind to estrogen receptors, it is widely hypothesized that the actions of isoflavones are mediated via the estrogen receptors. Typically, supplements provide $25-100 \mathrm{mg}$ total isoflavones if consumed according to package directions. ${ }^{6}$

Table 1: Baseline characteristics and time between measurements in subjects receiving isoflavone or placebo.

\begin{tabular}{|lllll|}
\hline S No. & Characteristics & $\begin{array}{l}\text { Isoflavone group } \\
(\mathbf{n}=44)\end{array}$ & $\begin{array}{l}\text { Placebo group } \\
(\mathbf{n}=41)\end{array}$ & P value \\
\hline 1. & Age $(\mathrm{y})($ Mean \pm SD) & $55.1 \pm 4.72$ & $55.2 \pm 4.9$ & 0.923 \\
\hline 2. & Years since menopause $($ Mean \pm SD) & $6.30 \pm 5.7$ & $5.99 \pm 3.91$ & 0.924 \\
\hline 3. & BMI $\left(\mathrm{kg} / \mathrm{m}^{2}\right)$ & $25.44 \underline{+4.18}$ & $25.53 \pm 4.7$ & 0.926 \\
\hline
\end{tabular}


In this study there was a slight decrease in bone mineral density in study groups, but the decrease in treatment group was much less than control group and this difference was found statistically significant. This is similar to many studies that have been conducted to examine the effects of soy on bone mineral density in peri and post-menopausal women. Majority of these found that BMD was significantly higher after supplementation with isoflavone tablets.

Table 2: Effects of isoflavones upon bone mineral density.

\begin{tabular}{|lllllll|}
\hline & \multicolumn{2}{c}{ Treatment group } & P value & \multicolumn{2}{c}{ Placebo group } & P value \\
\hline Femur neck & 0 months & 12 months & & 0 months & 12 months \\
\hline Lumbar spine & $0.84 \pm 0.12$ & $0.90 \pm 0.12$ & 0.015 & $0.82 \pm 0.10$ & $0.84 \pm 0.10$ & 0.06 \\
\hline
\end{tabular}

\section{CONCLUSIONS}

From the present study we concluded that phytoestrogen isoflavones can be used effectively to control peri and post-menopausal bone loss. Further long term extended longitudinal studies are required to not only assess potential serum alteration but also to ascertain the long term beneficial effect of this herbal non-hormonal mode of therapy.

\section{Funding: No funding sources}

Conflict of interest: None declared

Ethical approval: The study was approved by the Institutional Ethics Committee

\section{REFERENCES}

1. NIH consensus development panel on osteoporosis prevention, diagnosis and therapy. South Med J. 2001;94:569-73.
2. Sowers MF, Galuska DA. Epidemiology of bone mass in premenopausal women. Epidemiol Rev. 1933;15:374-98.

3. Khan AA, Syed Z. Bone densitometry in premenopausal women: synthesis and review. J Clin Densitom. 2004;7(1):85-92.

4. Mann GB , Kang YC,Brand C, Ebeling PR ,Miller JA. Secondary causes of low bone mass in patients with breast cancer. A need for greater vigilance. J Clin Oncol. 2009;18(4):85-9.

5. Vatanparast H, Chilibeck PD. Does the effect of soy phytoestrogens on bone in postmenopausal women depend on the equol-produsing phenotype? Nutr Rev. 2007;65(6 Pt-1):294-9.

6. Fragakis AS. The Health Professionals Guide to popular Dietary Supplements. $2^{\text {nd }}$ edition. Chicago IL: American Dietetic Association, 2003.

Cite this article as: Singh N, Kumar D, Dubey P, Chandanan A, Singh P. The effects of isoflavones on bone density in postmenopausal women at tertiary centre. Int J Reprod Contracept Obstet Gynecol 2015;4:1763-5. 